\title{
A case of lethal soft tissue injuries due to assault
}

This article was published in the following Dove Press journal:

Open Access Emergency Medicine

26 May 2012

Number of times this article has been viewed

\section{Youichi Yanagawa' \\ Yoshimasa Kanawaku² \\ Jun Kanetake 2 \\ 'Department of Emergency and Disaster Medicine, Juntendo University, Tokyo, ${ }^{2}$ Department of Forensic Medicine, National Defense Medical College, Saitama, Japan}

Correspondence: Youichi Yanagawa Department of Emergency and Disaster Medicine, Juntendo University 3-I-3, Hongo Bunkyo-ku, Tokyo, Japan I|3-843 |

$\mathrm{Tel}+8|338| 33|\mathrm{I}|$

Fax +8I3 58423176

Email yyanaga@juntendo.ac.jp
Abstract: A 42-year-old male had been assaulted by his family over the two previous days and went into a deep coma. When the emergency technician arrived, the patient was in a state of cardiopulmonary arrest. On arrival, his electrocardiogram showed asystole. His body showed swelling with subcutaneous hemorrhage, suggesting multiple contusional wounds. Serum biochemistry evaluation revealed blood urea nitrogen of $80 \mathrm{mg} / \mathrm{dL}$, creatinine of $5.99 \mathrm{mg} / \mathrm{dL}$, creatine phosphokinase of 10,094 IU/L, and potassium of $11.0 \mathrm{mEq} / \mathrm{L}$. Advanced cardiopulmonary resuscitation failed to obtain a return of spontaneous circulation. Laboratory findings revealed rhabdomyolysis, renal failure, and hyperkalemia. Autopsy did not indicate the direct cause of death to be traumatic organ injuries. Because trauma was not the direct reason of death, we speculated that the patient died of hyperkalemia induced by multiple contusional soft tissue injuries, following rhabdomyolysis, hemolysis, and acute renal failure. The physician should maintain a high index of suspicion for hyperkalemia induced by rhabdomyolysis and acute renal failure, especially in patients presenting with symptoms of multiple soft tissue injuries with massive subcutaneous hemorrhaging.

Keywords: contusion, rhabdomyolysis, renal failure, hyperkalemia

\section{Introduction}

The major causes of rhabdomyolysis are pharmacological or related to trauma, compression, exertion, convulsions, myositis, heat stroke, muscle metabolic disease (mitochondrial cytopathy, glycogen storage disease), malignant hyperthermia, neuroleptic malignant syndrome, viral or bacterial infections, multiple myeloma, and wasp stings. ${ }^{1-3}$ Among these, pharmacological and trauma-related rhabdomyolysis occurs more frequently than the other conditions.

Rhabdomyolysis leads to the production of myotoxins, including myoglobin, which results in the complication of acute renal failure, followed by hyperkalemia and death if appropriate treatments are not administered. ${ }^{4,5}$ The estimated rate of the complication of acute renal failure produced by rhabdomyolysis is over $33 \%$, and the rate of death is approximately $3 \% .{ }^{1}$ With regard to trauma, immobilization of the human body by the collapse of a structure during an earthquake leads to crush syndrome, and such victims who do not undergo proper treatment may die of hyperkalemia soon after rescue, even if conscious. ${ }^{6,7}$ However, to the best of our knowledge, lethal hyperkalemia induced by simple contusional soft tissue injuries resulting from an assault has not been reported. We herein report our experience with such a case. 


\section{Case report}

A 42-year-old male had been assaulted by his family over the previous two days for money-related reasons. He finally went into a deep coma and ceased breathing, so an emergency call was made. When the emergency technician arrived, the patient was in a state of cardiopulmonary arrest. An electrocardiogram at the scene showed pulseless electrical activity. He was transferred to our department without a return of spontaneous circulation. On arrival, he remained in a state of cardiopulmonary arrest. The electrocardiogram showed asystole. His pupils were dilated and nonreactive to light stimulation. His face, head, left upper extremities, and upper back had swelling with subcutaneous hemorrhage, suggesting multiple contusional wounds (Figure 1). Advanced cardiopulmonary resuscitation failed to produce a return of spontaneous circulation.

Post mortem computed tomography revealed a small amount of intraventricular hemorrhage and minute subdural hemorrhage in his head, fractures of the back side of his ribs, a small amount of hemothorax, and fractures of the transverse process in the lumbar spine in his trunk. Both kidneys were of normal size. Serum biochemistry evaluation revealed aspartate aminotransferase of $1002 \mathrm{IU} / \mathrm{L}$, alanine aminotransferase of $775 \mathrm{IU} / \mathrm{L}$, blood urea nitrogen of $80 \mathrm{mg} / \mathrm{dL}$, creatinine of $5.99 \mathrm{mg} / \mathrm{dL}$, creatine phosphokinase of 10,094 IU/L, potassium of $11.0 \mathrm{mEq} / \mathrm{L}$, suggesting liver injury, rhabdomyolysis, renal failure, and hyperkalemia. The autopsy did not indicate any direct injury leading to death. Because trauma was not the direct reason for his death, we speculated that the patient died of hyperkalemia induced by multiple contusional soft tissue injuries, following rhabdomyolysis, hemolysis, and acute renal failure.

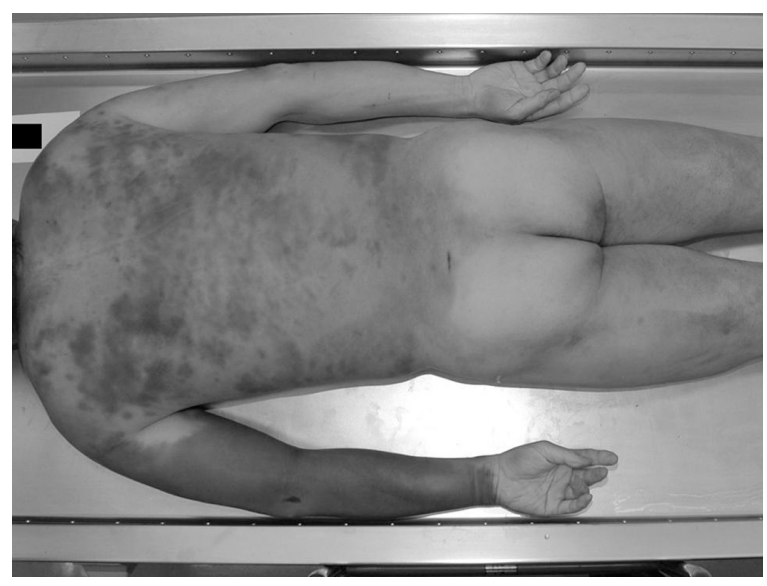

Figure I Macroscopic findings on the back of the patient.

Note: Examination revealed subcutaneous hemorrhage in the left upper extremity and upper back, suggesting multiple contusional wounds.

\section{Discussion}

This is the first case report showing that multiple contusional soft tissue injuries due to an assault can result in rhabdomyolysis, hemolysis, renal failure, hyperkalemia, and eventually death based on the results of laboratory examinations, whole body computed tomography, and autopsy. A serum creatine phosphokinase level $>5000 \mathrm{IU} / \mathrm{L}$ increases the ability to predict which patients will develop acute renal failure requiring dialysis. ${ }^{8}$ In addition, mechanical hemolysis including trauma itself can cause acute renal failure and hyperkalemia. ${ }^{9}$ In addition, post mortem hemolysis can increase potassium levels, which has a positive relationship with the duration from cardiac arrest to measurement. ${ }^{10,11}$ However, this case demonstrated pulseless electrical activity at the scene, and therefore the duration of cardiac arrest was thought to be short in comparison with asystole. Accordingly, the possibility that hyperkalemia had been induced by post mortem hemolysis was thus minimized. Rhabdomyolysis and renal failure caused by muscle injury, such as crush syndrome, is well known, but our case adds one more cause to the list of documented etiologies of death as a result of soft tissue injuries due to assault.

The diagnosis of rhabdomyolysis is determined based on increasing values of serum creatinine phosphokinase. If the patient complains of muscle pain, muscle swelling, or brown cola-like urine after muscle injury or following treatment with psychotropic drugs or statins, a diagnosis of rhabdomyolysis is not difficult. However, hyperkalemia induced by rhabdomyolysis, hemolysis, and acute renal failure might be asymptomatic, and if not diagnosed correctly and treated aggressively, can result in death. ${ }^{12,13}$ Accordingly, a physician should maintain a high index of suspicion for hyperkalemia induced by rhabdomyolysis and acute renal failure, especially in patients with symptoms of multiple soft tissue injuries, including massive subcutaneous hemorrhaging.

\section{Disclosure}

The authors report no conflicts of interest in this work.

\section{References}

1. Sharp LS, Rozycki GS, Feliciano DV. Rhabdomyolysis and secondary renal failure in critically ill surgical patients. Am J Surg. 2004;188(6): 801-806

2. Russell TA. Acute renal failure related to rhabdomyolysis: pathophysiology, diagnosis, and collaborative management. Nephrol Nurs J. 2000;27(6): 567-575

3. Paudel B, Paudel K. A study of wasp bites in a tertiary hospital of western Nepal. Nepal Med Coll J. 2009;11(1):52-56.

4. Oda J, Tanaka H, Yoshioka T, et al. Analysis of 372 patients with crush syndrome caused by the Hanshin-Awaji earthquake. JTrauma. 1997;42(3): $470-475$. 
5. Melli G, Chaudhry V, Cornblath DR. Rhabdomyolysis: an evaluation of 475 hospitalized patients. Medicine (Baltimore). 2005;84(6): 377-385.

6. Line RL, Rust GS. Acute exertional rhabdomyolysis. Am Fam Physician. 1995;52(2):502-506.

7. Lima RS, da Silva Junior GB, Liborio AB, Daher Ede F. Acute kidney injury due to rhabdomyolysis. Saudi J Kidney Dis Transpl. 2008;19(5): 721-729.

8. Köppel C. Clinical features, pathogenesis and management of druginduced rhabdomyolysis. Med Toxicol Adverse Drug Exp. 1989;4(2): $108-126$.

9. Geddes LA, Roeder RA, Rundell AE, Otlewski MP, Kemeny AE, Lottes AE. The natural biochemical changes during ventricular fibrillation with cardiopulmonary resuscitation and the onset of postdefibrillation pulseless electrical activity. Am J Emerg Med. 2006;24(5):577-581.
10. Garcia MC, Ebeo CT, Byrd RP Jr, Roy TM. Rhabdomyolysis associated with pneumococcal pneumonia: an early clinical indicator of increased morbidity? Tenn Med. 2002;95(2):67-69.

11. Dukkipati R, Yang EH, Adler S, Vintch J. Acute kidney injury caused by intravascular hemolysis after mechanical thrombectomy. Nat Clin Pract Nephrol. 2009;5(2):112-116.

12. Atef-Zafarmand A, Fadem S. Disaster nephrology: medical perspective. Adv Ren Replace Ther. 2003;10(2):104-116.

13. Yanagawa Y, Sakamoto T, Sato H. Relationship between laboratory findings and the outcome of cardiopulmonary arrest. Am JEmerg Med. 2009;27(3):308-312.

\section{Publish your work in this journal}

Open Access Emergency Medicine is an international, peer-reviewed, open access journal publishing original research, reports, editorials, reviews and commentaries on all aspects of emergency medicine. The manuscript management system is completely online and includes a very quick and fair peer-review system, which is all easy to use.

\section{Dovepress}

Visit http://www.dovepress.com/testimonials.php to read real quotes from published authors. 